\title{
Association between NAT2, CYP1A1, and CYP1A2 genotypes, heterocyclic aromatic amines, and prostate cancer risk: a case control study in Japan
}

\author{
Masahide Koda ${ }^{1 *}$, Motoki Iwasaki $^{2}$, Yuko Yamano ${ }^{3}$, Xi Lu and Takahiko Katoh
}

\begin{abstract}
Background: Heterocyclic aromatic amines (HAAs) may confer prostate cancer risk; however, the evidence is inconclusive and the activity of HAA-metabolizing enzymes is modulated by gene variants. The purpose of our study was to determine whether there was evidence of an association between HAA intake, polymorphisms in NAT2, CYP1A1, and CYP1A2 and prostate cancer risk in Japanese men.
\end{abstract}

Methods: Secondary data analysis of an observational case control study was performed. Among 750 patients with prostate cancer and 870 healthy controls, 351 cases and 351 age-matched controls were enrolled for analysis. HAA intake was estimated using a food frequency questionnaire and genotypes were scored by TaqMan real-time PCR assay. Logistic regression analysis was conducted according to affected/control status.

Results: We found that high HAA intake was significantly associated with an increased risk of prostate cancer (odds ratio (OR), 1.90; 95\% confidence interval $(95 \% \mathrm{Cl}), 1.40-2.59)$. The increased risk of prostate cancer was observed among individuals with the NAT2 slow acetylator phenotype (OR, 1.65; 95\% Cl, 1.04-2.61), CYP1A1 GA + GG genotype (OR, 1.27; 95\% Cl, 1.02-1.59), and CYP1A2 CA + AA genotype (OR, 1.43; 95\% Cl, 1.03-2.00). In addition, CYP1A1 GA + GG genotypes were associated with increased cancer risk in low $(\mathrm{OR}, 2.05 ; 95 \% \mathrm{Cl}, 1.19-3.63)$, moderate $(\mathrm{OR}, 1.72 ; 95 \% \mathrm{Cl}, 1.07-2.76)$, and high $(\mathrm{OR}, 2.86 ; 95 \% \mathrm{Cl}, 1.83-4.47)$ HAA intake groups.

Conclusions: Our results suggest that high HAA intake is a risk factor of prostate cancer, and genotypes related to HAA metabolic enzymes can modulate the degree of the risk.

Keywords: Prostate cancer, NAT2, CYP1A1, CYP1A2, Heterocyclic aromatic amines

\section{Background}

It has been proposed that high consumption of meat, including red and processed meat as well as fish, confers risk of prostate cancer [1-5]. Heterocyclic aromatic amines (HAAs), which are known mutagens formed in cooked meat and fish at high temperatures, are considered the causative agents for the association between meat intake and prostate cancer risk [2, 6-8].

HAAs can metabolically result in carcinogenesis through the formation of HAA-DNA adducts [9-11], which lead

\footnotetext{
* Correspondence: shoei05-kmi@umin.ac.jp

${ }^{1}$ Department of Public Health, Faculty of Life Sciences, Kumamoto University, 1-1-1 Honjou, Chuo-ku, Kumamoto 860-8556, Japan

Full list of author information is available at the end of the article
}

to tumor formation by conferring mutations in genes that control cell proliferation [12]. In addition, it was shown that human prostate cells metabolize HAAs to a carcinogenic state by forming HAA-DNA adducts after exposure to HAAs in vivo $[8,13-16]$.

Several studies have investigated whether there is an association between dietary HAA intake and prostate cancer risk; however, results were suggestive yet inconclusive $[1,3,17,18]$. This disparity reflects two main reasons. First, it is difficult to assess dietary HAA intake, the composition of which varies according to the cooking method and meat type $[19,20]$. In Japan, several studies investigated prostate cancer risk, using only meat and fish intake $[21,22]$; however, no prior study has 
investigated the risk by estimating the dietary HAA intake. Typically, Japanese elderly people intake more fish than meat, and they prefer chopping and stir-frying their meat to grilling [23, 24]. Foods that contribute to HAA intake differ by country [25]; therefore, dietary assessment tools for HAA intake should be tailored specifically to the population being studied.

The second reason is the difficulty in assessing a study population in terms of metabolic variation determined by genetic heterogeneity. Similar to other environmental chemical carcinogens, it is necessary for HAAs to be metabolically activated by host enzymes to acquire genetic toxicity. Phase I enzymes such as cytochrome P450 (CYP) enable HAAs to metabolically activate and, thus, form genotoxic electrophilic intermediates [26]. This transition enables phase II enzymes, including $N$-acetyltransferase 1 (NAT1) and $N$-acetyltransferase 2 (NAT2), to detoxify part of the activated metabolites by performing the tasks of $\mathrm{N}$ acetylation and $\mathrm{O}$-acetylation [27]. It is presumed that the relative activities of these metabolizing enzymes, which are mostly genetically determined, have a critical role in HAA-mediated prostate cancer development.

In the phase I cytochrome P450 family, CYP1A1 and $C Y P 1 A 2$ are highly active in the liver and play a major role in the metabolic activation of HAAs, and each enzyme activity has been considered to be linked to genetic variations [18, 28, 29]. In phase II enzymes, previous studies suggested that the genetic polymorphisms in NAT1 and/or NAT2 may modify prostate cancer risk related to exposure to HAA carcinogens [30]. The frequencies of NAT1 and NAT2 genotype varies according to racial and ethnic background, and the frequency difference may be a factor in cancer incidence [31]. Although NAT1 is expressed in the prostate, the relationship between the NAT1 genotype and phenotype in a Japanese population remains unclear [32]. On the other hand, NAT2 is expressed predominantly in the liver, and the relationship between genetic variants of NAT2 and the acetylator phenotype in Japanese individuals is clear [31, 33-35]. It is considered that the NAT2 slow acetylator phenotype would increase the prostate cancer risk because this phenotype would have reduced hepatic $\mathrm{N}$ acetylation for detoxification of HAA carcinogens, thus increasing the chance of hepatic N-hydroxylation for activation [36].

Therefore, in this study, we used a validated assessment food frequency questionnaire (FFQ) to assess dietary HAAs in Japanese cultural contexts $[25,37,38]$ and investigated the phenotypes and genotypes of NAT2, CYP1A1, and CYP1A2 in our subjects. To the best of our knowledge, no prior reports have investigated the relationship between NAT2, CYP1A1, and CYP1A2 polymorphisms and HAAs as risk factors for prostate cancer in a Japanese population. The purpose of this study was to determine the impact of HAA intake and genetic polymorphisms in NAT2, CYP1A1, and CYP1A2 on prostate cancer in Japanese men.

\section{Methods \\ Design}

This study was a secondary data analysis of an observational case control study. Written informed consent was obtained from all subjects by the return of the questionnaires. The study protocol received ethics approval by the institutional review board of Faculty of Life Sciences, Kumamoto University (Kumamoto, Japan), on June 10, 2016 (approval number 209). The first and last authors take all responsibility for the integrity of the data and the accuracy of the data analysis.

\section{Subjects}

We identified 750 eligible male patients between 40 to 90 years of age who were diagnosed with histologically confirmed prostate cancer at the Jikei University School of Medicine Hospital (Tokyo, Japan) from August 2004 to December 2006. We also identified 870 men as prospective controls in the same age range who (i) underwent comprehensive medical examination for health screening at the Mitsui Memorial Hospital (Tokyo, Japan) during the same survey period, (ii) exhibited no evidence of prostate cancer as determined by blood test (PSA $<4 \mathrm{mg} / \mathrm{dL}$ ), and (iii) provided consent for participation. Because age is a known risk factor for prostate cancer, we selected age-adjusted control subjects according to the average age of our affected group and identified 351 cases and 351 controls for analysis.

\section{Exposure assessment}

Subjects completed a self-administered questionnaire regarding general characteristics: age, sex, height, weight, occupation, smoking and drinking habits, dietary habits, personal medical history, and family history including prostate cancer. Food and beverage consumption was assessed with a food frequency questionnaire (FFQ) [23] that consists of 138 food and beverage items, which asks to report the usual consumption of the listed foods during the past year. Frequency response choices for food items consisted of nine options: less than once per month, 1-3 times per month, 1-2 times per week, 3-4 times per week, 5-6 times per week, once per day, 2-3 times per day, 4-6 times per day, and 7 or more times per day. Further, standard portion sizes were selected for each food item with three choices: medium (standard), small (50\% smaller), and large (50\% larger).

HAA consumption is a different parameter in meat and fish consumption. For fish, HAA intake was estimated from 19 kinds of items: salted fish, semi-dried split fish, salmon, horse mackerel or sardines, Pacific saury or mackerel, and 
eel from six groups. In addition, participants were asked about grilled skin consumption using five quantity categories: almost none, one-third, half, two-thirds, and almost all. HAA intake from fish consumption was then estimated based on the proportion of grilled to total fish consumption, the rate of grilled skin consumption, the ratio of skinto-flesh, and data on HAA content in the skin and flesh.

Similarly, HAA intake from meat was estimated according to 7 of 18 meat items: pan-fired and grilled beef, stir-fried pork and pork liver, grilled chicken and chicken liver, and bacon. Participants reported their preferred grilled level of pan-fried and grilled beef among five categories: very well-done, well-done, medium, medium rare, and rare. HAA intake consumption was then estimated based on this information and data on HAA content, which were validated measurements of 2-amino-1methyl-6-phenylimidazo[4,5-b]pyridine (PhIP) levels in the hair from a prior study $[25,37,38]$.

\section{Genotyping}

Blood samples were obtained from all participants and collected during the protocol period before a procedure was performed. Buffy coats were preserved at $-80{ }^{\circ} \mathrm{C}$ soon after blood sampling until analysis. Pre-validated allelic discrimination TaqMan real-time PCR (Applied Biosystems, Foster City, CA, USA) was used for genotyping of single nucleotide polymorphisms (SNPs). The reaction solution $(9 \mu \mathrm{L})$ was aliquoted into each well of a 48 -well reaction plate, and $1 \mu \mathrm{L}$ of DNA or water control was added to each tube.

NAT2 slow acetylator alleles were reported as: NAT2*5 (rs1801280: T > C), NAT2*6 (rs1799930: G > A), and NAT2*7 (rs1799931: G > A). Although NAT2*13 (rs1208: A $>$ G) was previously considered among slow acetylator alleles, recent studies have indicated that alleles of $N A T 2 * 4$ and NAT2*13 dominantly determine the fast acetylator phenotype [31-35]. Slow acetylators were classified if individuals have at least two variant alleles, and intermediate acetylators were categorized as those individuals having one slow acetylator allele from these loci. Genotyping of rs1048943 (A > G) at CYP1A1 and rs762551 $(\mathrm{A}>\mathrm{G})$ at $C Y P 1 A 2$ was also undertaken.

\section{Statistical analysis}

For demographic and clinical data, we used the chi-square test to compare proportions of categorical variables and the Mann-Whitney test to compare the averages of continuous variables between groups. Conditional logistic regression models were used to evaluate the relationship between HAA intake and genotype. Our models were adjusted for variables associated with prostate cancer identified either by the current study or by previous studies [39-41] and included alcohol consumption, smoking status, body mass index (BMI), family history of prostate cancer, and total energy intake. Intake of HAA and other nutrients and foods was adjusted for total energy intake using the residual model [42]. HAA intake was divided into tertile categories and evaluated using the CochranArmitage test for trend. To identify associations between HAA intake and polymorphisms of tested genes, we assessed HAA intake based on subgrouping subjects as "rapid/intermediate" or "slow" for NAT2 as well as by variant alleles, and by those with two wild-type alleles for CYP1A1 and CYP1A2. The threshold for significance was $P<0.05$. All statistical analyses were conducted using SPSS version 21 (IBM Corp., Armonk, NY, USA).

\section{Results}

The general characteristics of our cohorts are presented in Table 1. This study included 351 patients with prostate cancer with a pathologically confirmed diagnosis and 351 cancer-free controls, aged from 50 to 79 years of age. The average age in both groups was 64.9 years. We observed that a significantly higher rate of family history of prostate cancer was found in cases compared to that in controls, while the rate of alcohol consumption was lower in cases compared to that in controls. Although we found no differences in BMI and total energy intake between the two groups, we found significantly higher rates of the following measures in cases compared to those in controls: total HAA intake; 3-amino-1, 4-dimethyl-5H-pyrido[4, 3-b]indole (Trp-P-1); 2-amino3-methylimidazo[4, 5-f]quinoline (IQ); 2-amino-3, 4dimethylimidazo[4, 5-f] quinoline (MeIQ); 2-amino-3, 8dimethylimidazo[4, 5-f]quinoxaline (MeIQx); and PhIP. We found no statistically significant differences between cohorts for other variables including meat, red meat, processed meat, vegetable, and salt $(\mathrm{NaCl})$ intake as well as the rate of those who prefer their meat well done or ate almost all burnt fish skin.

As shown in Table 2, the distribution of genotyped SNPs was NAT2*5 (rs1801280), NAT2*6 (rs1799930), NAT2*7 (rs1799931), NAT2*13 (rs1208), CYP1A1 (rs1048943), and CYP1A2 (rs762551). Genotype frequencies of each SNP were consistent with Hardy-Weinberg equilibrium among controls.

Multivariate odds ratios (ORs) for HAA intake were analyzed, and several HAA-related measures with high intake were significantly associated with an increased risk of prostate cancer compared to controls (Table 3): total HAA (OR, 1.90; 95\% confidence interval (95\% CI), 1.40-2.59), Trp-P-1 (OR, 1.92; 95\% CI, 1.42-2.61), MeIQ (OR, 1.87; 95\% CI, 1.38-2.55), MeIQx (OR, 2.25; 95\% CI, 1.65-3.06), and PhIP (OR, 1.84; 95\% CI, 1.35-2.50).

Multivariate ORs for the NAT2-imputed phenotype and the CYP1A1 and CYP1A2 genotypes are shown in Table 4. We found that the factors associated with a significantly increased risk of prostate cancer were the 
Table 1 Characteristics of cases and controls

\begin{tabular}{|c|c|c|c|}
\hline Characteristics & Cases & Controls & $P$ \\
\hline Number & 351 & 351 & \\
\hline Age, years; mean (SD) & $64.9(0.35)$ & $64.9(0.35)$ & $1.00^{\mathrm{b}}$ \\
\hline$<65 ; n(\%)$ & $180(51.3 \%)$ & $180(51.3 \%)$ & \\
\hline$\geq 65 ; n(\%)$ & $171(48.7 \%)$ & $171(48.7 \%)$ & $1.00^{\mathrm{a}}$ \\
\hline Family history of prostate cancer; $n$ (\%) & $13(3.7 \%)$ & $4(1.1 \%)$ & $0.027^{\mathrm{a}}$ \\
\hline Alcohol consumption, g/week; mean (SD) & $151.6(192.4)$ & $196.0(207.2)$ & $<0.001^{b}$ \\
\hline \multicolumn{4}{|l|}{ Smoking status; $n$ (\%) } \\
\hline Never & $126(35.9 \%)$ & $108(30.8 \%)$ & \\
\hline Ever & $225(64.1 \%)$ & $243(69.2 \%)$ & $0.15^{\mathrm{a}}$ \\
\hline Current smoker & $55(15.7 \%)$ & $67(19.1 \%)$ & $0.23^{\mathrm{a}}$ \\
\hline Ex-smoker & $170(48.4 \%)$ & $176(50.1 \%)$ & $0.65^{\mathrm{a}}$ \\
\hline $\mathrm{BMl}, \mathrm{kg} / \mathrm{m}^{2}$; mean (SD) & $23.8(0.14)$ & $23.8(0.13)$ & $1.00^{\mathrm{b}}$ \\
\hline Total HAA intake, ng/day; mean (SD) & $46.5(1.6)$ & $38.2(1.7)$ & $<0.001^{\mathrm{b}}$ \\
\hline Trp-P-1 intake & $3.9(0.23)$ & $3.1(0.19)$ & $<0.001^{\mathrm{b}}$ \\
\hline IQ intake & $0.32(0.021)$ & $0.27(0.018)$ & $0.012^{\mathrm{b}}$ \\
\hline MelQ intake & $5.9(0.21)$ & $4.8(0.17)$ & $<0.001^{\mathrm{b}}$ \\
\hline MelQx intake & $6.4(0.21)$ & $5.2(0.20)$ & $<0.001^{\mathrm{b}}$ \\
\hline 4,8-DiMelQx intake & $0.41(0.34)$ & $0.36(0.33)$ & $0.10^{\mathrm{b}}$ \\
\hline 7,8-DiMelQx intake & $1.6(0.14)$ & $1.4(0.14)$ & $0.06^{\mathrm{b}}$ \\
\hline PhIP intake & $28.2(0.98)$ & $23.3(0.93)$ & $<0.001^{b}$ \\
\hline Total energy intake, kcal/day; mean (SD) & $1869.2(567.8)$ & $1789.3(519.9)$ & $0.30^{\mathrm{b}}$ \\
\hline Meat intake, g/day; mean (SD) & $59.9(41.0)$ & $50.2(36.1)$ & $0.84^{b}$ \\
\hline Red meat intake, g/day; mean (SD) & $47.3(33.8)$ & $37.6(31.0)$ & $0.87^{\mathrm{b}}$ \\
\hline Processed meat intake, g/day; mean (SD) & $7.1(7.9)$ & $6.3(8.6)$ & $0.42^{b}$ \\
\hline Fish intake, g/day; mean (SD) & $84.2(58.3)$ & $77.4(62.8)$ & $0.51^{\mathrm{b}}$ \\
\hline Vegetable intake, g/day; mean (SD) & $88.7(68.4)$ & $82.7(73.2)$ & $0.24^{b}$ \\
\hline $\mathrm{NaCl}$ intake, g/day; mean (SD) & $10.1(4.5)$ & $9.2(4.1)$ & $0.79^{b}$ \\
\hline Participants with preference on meat cooked level as well done or very well done (\%) & $33(50.7 \%)$ & $26(44 \%)$ & $0.40^{\mathrm{a}}$ \\
\hline Participants with preference on eating almost all of grilled fish skin (\%) & $71(50.4 \%)$ & $70(49.6 \%)$ & $0.99^{\mathrm{a}}$ \\
\hline
\end{tabular}

$B M I$ body mass index; SD standard deviation; HAA heterocyclic aromatic amine; $\mathrm{NaCl}$ sodium chloride; $\operatorname{Trp}-\mathrm{P}$-1 3-Amino-1, 4-dimethyl-5H-pyrido[4, 3-b]indole; $I Q$ 2-Amino-3-methylimidazo[4,5-f]quinoline; MelQ 2-Amino-3,4-dimethylimidazo[4,5-f]quinoline; MelQx 2-Amino-3,8-dimethylimidazo[4,5-f]quinoxaline; 4,8-DiMelQx 2-Amino-3, 4, 8-trimethylimidazo[4, 5-f]quinoxaline; 7,8-DiMelQx 2-Amino-3, 7, 8-trimethylimidazo[4, 5-f]quinoxaline;

PhIP 2-Amino-1-methyl-6-phenylimidazo[4,5-b]pyridine

${ }^{\text {a } C h i-s q u a r e ~ t e s t ~}$

${ }^{\mathrm{b}}$ Mann-Whitney test

Table 2 SNPS and their allele frequencies in NAT2, CYP1A1, and CYP1A2

\begin{tabular}{cllll}
\hline & SNP rs $\#$ & Amino acid change & Major/minor allele & Major allele frequency in control group \\
\hline NAT2 & & lle114Thr & T/C & 0.986 \\
NAT2*5 & rs1801280 & Arg197Gln & G/A & 0.96 \\
NAT2*6 & rs1799930 & Gly286Glu & G/A & 0.641 \\
NAT2*7 & rs1799931 & Lys268Arg & A/G & 0.826 \\
NAT2*13 & rs1208 & lle462Val & A/G & 0.661 \\
CYP1A1 & rs1048943 & 5'-UTR & A/C & 0.379 \\
CYP1A2 & rs762551 & & \\
\hline
\end{tabular}


Table 3 Association between HAA intake and prostate cancer

\begin{tabular}{|c|c|c|c|c|}
\hline & Mean (SD) & Cases & Controls & OR $(95 \% \mathrm{Cl})^{\mathrm{a}}$ \\
\hline \multicolumn{5}{|l|}{ Total HAAs (ng/day) } \\
\hline Low tertile & $17.5(7.1)$ & 100 & 131 & 1.00 \\
\hline Moderate tertile & $35.6(5.3)$ & 108 & 124 & $\begin{array}{l}1.14 \\
(0.83 \\
-1.58)\end{array}$ \\
\hline High tertile & $72.9(29.2)$ & 143 & 96 & $\begin{array}{l}1.90 \\
(1.40 \\
-2.59)\end{array}$ \\
\hline Trend $\mathrm{P}^{\mathrm{b}}$ & & & & $<0.001$ \\
\hline \multicolumn{5}{|c|}{ Total Trp-P-1 (ng/day) } \\
\hline Low tertile & $0.44(0.55)$ & 104 & 129 & 1.00 \\
\hline Moderate tertile & $2.9(0.55)$ & 104 & 128 & $\begin{array}{l}1.05 \\
(0.76 \\
-1.45)\end{array}$ \\
\hline High tertile & $7.2(5.0)$ & 143 & 94 & $\begin{array}{l}1.92 \\
(1.42 \\
-2.61)\end{array}$ \\
\hline Trend $\mathrm{P}$ & & & & $<0.001$ \\
\hline \multicolumn{5}{|l|}{ Total MelQ (ng/day) } \\
\hline Low tertile & $2.3(0.93)$ & 100 & 131 & 1.00 \\
\hline Moderate tertile & $4.5(0.57)$ & 109 & 123 & $\begin{array}{l}1.18 \\
(0.85 \\
-1.63)\end{array}$ \\
\hline High tertile & $9.0(3.7)$ & 142 & 97 & $\begin{array}{l}1.87 \\
(1.38 \\
-2.55)\end{array}$ \\
\hline Trend $\mathrm{P}$ & & & & $<0.001$ \\
\hline \multicolumn{5}{|l|}{ Total MelQx (ng/day) } \\
\hline Low tertile & $2.4(0.98)$ & 99 & 132 & 1.00 \\
\hline Moderate tertile & $4.9(0.71)$ & 102 & 130 & $\begin{array}{l}1.05 \\
(0.76 \\
-1.46)\end{array}$ \\
\hline High tertile & $9.9(3.9)$ & 150 & 89 & $\begin{array}{l}2.25 \\
(1.65 \\
-3.06)\end{array}$ \\
\hline Trend $\mathrm{P}$ & & & & $<0.001$ \\
\hline \multicolumn{5}{|l|}{ Total PhIP (ng/day) } \\
\hline Low tertile & $10.5(4.2)$ & 102 & 129 & 1.00 \\
\hline Moderate tertile & $21.5(3.2)$ & 106 & 126 & $\begin{array}{l}1.06 \\
(0.77 \\
-1.48)\end{array}$ \\
\hline High tertile & $44.7(18.3)$ & 143 & 96 & $\begin{array}{l}1.84 \\
(1.35 \\
-2.50)\end{array}$ \\
\hline Trend P & & & & $<0.001$ \\
\hline
\end{tabular}

$B M I$ body mass index; OR oratio; $95 \% \mathrm{Cl} 95 \%$ confidence interval; HAA heterocyclic aromatic amine; Trp-P-1 3-Amino-1, 4-dimethyl-5H-pyrido[4, 3-b]indole; MelQ 2-Amino-3,4-dimethylimidazo[4,5-f]quinoline; MelQx 2-Amino3,8-dimethylimidazo[4,5-f]quinoxaline;

PhIP 2-Amino-1-methyl-6-phenylimidazo[4,5-b]pyridine

${ }^{\mathrm{a}} \mathrm{ORs}(95 \% \mathrm{Cl})$ adjusted by conditional logistic regression for alcohol intake, smoking status, BMI, family history of prostate cancer, and total energy intake ${ }^{\mathrm{b}} P$ value for Cochran-Armitage test for trend
Table 4 Association between NAT2-imputed phenotype, CYP1A1 and CYP1A2 genotype, and prostate cancer

\begin{tabular}{|c|c|c|c|c|}
\hline & Cases & Controls & $P$ & OR $(95 \% \mathrm{Cl})^{\mathrm{a}}$ \\
\hline \multicolumn{5}{|l|}{ NAT2-imputed phenotype } \\
\hline Rapid acetylator & 206 & 212 & & 1.00 \\
\hline Intermediate acetylator & 118 & 121 & 0.69 & $\begin{array}{l}1.05 \\
(0.83 \\
-1.32)\end{array}$ \\
\hline Slow acetylator & 27 & 18 & 0.034 & $\begin{array}{l}1.65 \\
(1.04 \\
-2.61)\end{array}$ \\
\hline \multicolumn{5}{|l|}{ CYPIA1 } \\
\hline$A A$ & 207 & 232 & & 1.00 \\
\hline GA & 119 & 105 & 0.12 & $\begin{array}{l}1.20 \\
(0.95 \\
-1.52)\end{array}$ \\
\hline GG & 25 & 14 & 0.023 & $\begin{array}{l}1.76 \\
(1.08 \\
-2.87)\end{array}$ \\
\hline $\mathrm{GA}+\mathrm{GG}$ & 144 & 119 & 0.034 & $\begin{array}{l}1.27 \\
(1.02 \\
-1.59)\end{array}$ \\
\hline \multicolumn{5}{|l|}{ CYPIA2 } \\
\hline$C C$ & 34 & 47 & & 1.00 \\
\hline$C A$ & 177 & 171 & 0.045 & $\begin{array}{c}1.43 \\
(1.01 \\
-2.03)\end{array}$ \\
\hline AA & 140 & 133 & 0.048 & $\begin{array}{l}1.44 \\
(1.00 \\
-2.06)\end{array}$ \\
\hline$C A+A A$ & 317 & 304 & 0.035 & $\begin{array}{l}1.43 \\
(1.03 \\
-2.00)\end{array}$ \\
\hline
\end{tabular}

$B M I$ body mass index, $O R$ odds ratio, $\mathrm{Cl}$ confidence interval

${ }^{\mathrm{a} O R}(95 \% \mathrm{Cl})$ adjusted by conditional logistic regression for alcohol intake,

smoking status, BMI, family history of prostate cancer, and total energy intake

NAT2 slow acetylator phenotype (OR, 1.65; 95\% CI, 1.04-2.61), the CYP1A1 GG genotype (OR, 1.76; 95\% $\mathrm{CI}, 1.08-2.87)$, the CYP1A1 GA + GG genotype (OR, 1.27; 95\% CI, 1.02-1.59), the CYP1A2 CA genotype (OR, 1.43; 95\% CI, 1.01-2.03), the CYP1A2 AA genotype (OR, 1.44; $95 \% \mathrm{CI}, 1.00-2.06)$, and the CYP1A2 CA + AA genotype (OR, 1.43; 95\% CI, 1.03-2.00).

Analyses of combinations between HAA intake and NAT2-imputed phenotype and CYP1A1 and CYP1A2 genotypes are shown in Table 5. High HAA intake was associated with an increased risk of prostate cancer among each genotype and NAT-imputed phenotype, with the exception of the CYP1A2 CC genotype (OR, 2.65; 95\% CI, 0.97-7.29; $P$ for interaction, 0.003). In addition, among high HAA intake individuals, the risk was indicated by the phenotypes or genotypes, which were suggested from the result of Table 4. NAT2 slow acetylator phenotype, CYP1A1 GA + GG, and CYP1A2 CA + AA had higher OR than other paired phenotypes or genotypes as follows: 
Table 5 Prostate cancer risk and HAA intake stratified by NAT2-imputed phenotype and CYP1A1 and CYP1A2 genotype

\begin{tabular}{|c|c|c|c|c|}
\hline & \multicolumn{3}{|l|}{ HAA intake } & \multirow[b]{2}{*}{$P_{\text {interaction }}$} \\
\hline & Low & Moderate & High & \\
\hline \multicolumn{5}{|c|}{ NAT2-imputed phenotype } \\
\hline \multicolumn{5}{|c|}{ Rapid or intermediate acetylator } \\
\hline Cases/Controls & $92 / 124$ & $100 / 116$ & $132 / 93$ & \\
\hline OR $(95 \% C l)^{a}$ & 1.00 & $\begin{array}{l}1.17 \\
(0.84 \\
-1.65)\end{array}$ & $\begin{array}{l}1.85 \\
(1.34 \\
-2.56)\end{array}$ & \\
\hline \multicolumn{5}{|l|}{ Slow acetylator } \\
\hline Cases/Controls & $8 / 7$ & $8 / 8$ & $11 / 3$ & \\
\hline OR $(95 \% \mathrm{Cl})$ & $\begin{array}{l}1.43(0.50 \\
-4.12)\end{array}$ & $\begin{array}{l}1.21 \\
(0.56 \\
-2.60)\end{array}$ & $\begin{array}{l}5.29 \\
(2.37 \\
-11.80)\end{array}$ & 0.004 \\
\hline \multicolumn{5}{|l|}{ CYP1A1 } \\
\hline \multicolumn{5}{|l|}{ AA } \\
\hline Cases/controls & $51 / 87$ & $68 / 82$ & $88 / 63$ & \\
\hline OR $(95 \% \mathrm{Cl})$ & 1.00 & $\begin{array}{l}1.46 \\
(0.95 \\
-2.24)\end{array}$ & $\begin{array}{l}2.41 \\
(1.61 \\
-3.63)\end{array}$ & \\
\hline \multicolumn{5}{|l|}{$G A+G G$} \\
\hline Cases/controls & $49 / 44$ & $40 / 42$ & $55 / 33$ & \\
\hline OR $(95 \% \mathrm{Cl})$ & $\begin{array}{l}2.05(1.19 \\
-3.63)\end{array}$ & $\begin{array}{l}1.72 \\
(1.07 \\
-2.76)\end{array}$ & $\begin{array}{l}2.86 \\
(1.83 \\
-4.47)\end{array}$ & $<0.001$ \\
\hline \multicolumn{5}{|l|}{ CYP1A2 } \\
\hline \multicolumn{5}{|l|}{$\mathrm{CC}$} \\
\hline Cases/controls & $7 / 17$ & $14 / 17$ & $13 / 13$ & \\
\hline OR (95\% Cl) & 1.00 & $\begin{array}{l}2.05 \\
(0.73 \\
-5.77)\end{array}$ & $\begin{array}{l}2.65 \\
(0.97 \\
-7.29)\end{array}$ & \\
\hline \multicolumn{5}{|l|}{$C A+A A$} \\
\hline Cases/controls & $93 / 114$ & $94 / 107$ & $130 / 83$ & \\
\hline OR $(95 \% \mathrm{Cl})$ & $\begin{array}{l}2.17(0.85 \\
-5.59)\end{array}$ & $\begin{array}{l}2.34(0.93 \\
-5.92)\end{array}$ & $\begin{array}{l}4.01 \\
(1.60 \\
-10.05)\end{array}$ & 0.003 \\
\hline
\end{tabular}

$B M I$ body mass index, $O R$ odds ratio, $\mathrm{Cl}$ confidence interval, $\mathrm{HAA}$ heterocyclic aromatic amine

${ }^{a} \mathrm{OR}(95 \% \mathrm{Cl})$ adjusted by conditional logistic regression for alcohol intake, smoking status, BMI, family history of prostate cancer, and total energy intake

the NAT2 slow acetylator phenotype (OR, 5.29; 95\% CI, 2.37-11.80; $P$ for interaction, 0.004) was higher than the rapid or intermediate acetylator phenotype (OR, 1.85; 95\% CI, 1.34-2.56); the CYP1A1 GA + GG genotype (OR, 2.86; 95\% CI, 1.83-4.47) was higher than the AA genotype (OR, 2.41; 95\% CI, 1.61-3.63); and the CYP1A2 CA + AA genotype (OR, 4.01; 95\% CI, 1.60-10.05) was higher than the CC genotype (OR, 2.65; 95\% CI 0.97-7.29) even though the CC genotype OR is not statistically significant. Among individuals from the CYP1A1 GA + GG genotype group ( $P$ for interaction, $<0.001$ ), we found there was an association between increased risk of prostate cancer and all three HAA intake groups specifically low (OR, 2.05; 95\% CI, 1.19-3.63), intermediate (OR, 1.72; 95\% CI, 1.072.76), and high (OR, 2.86; 95\% CI, 1.83-4.47).

\section{Discussion}

This is the first national study which investigates the association between dietary HAA intake by using FFQ for estimate the amount of HAA, HAA-metabolic polymorphisms, and prostate cancer risk in Japanese people. We found that a high HAA intake was significantly associated with an increased risk of prostate cancer (Table 3), and the NAT2 slow acetylator phenotype, the CYP1A1 GG and GA + GG genotypes, and the CYP1A2 CA, AA, and $\mathrm{CA}+\mathrm{AA}$ genotypes were associated with an increased prostate cancer risk in our affected cohort with compared with the controls (Table 4). In addition, the CYP1A1 GA + GG genotype was associated with prostate cancer in low, moderate, and high HAA intake groups (Tables 4 and 5). These results support our hypothesis that high HAA 
intake is a risk factor of prostate cancer, and the degree of risk is influenced by polymorphisms in genes encoding HAA metabolic enzymes.

Previous studies have shown confounding results on whether there is an association between HAA intake and prostate cancer risk $[1,3,17,18]$. In Japanese, several studies specifically investigated the risk of only meat and fish intake to prostate cancer [21, 22], but no prior study investigated the association between dietary HAAs and prostate cancer risk in a Japanese population. The main reason for the absence of such a study is because of the difficulty in assessing dietary HAA intake. The HAA composition of cooked meat and fish varies depending on the cooking method and meat type [19, 20]. In addition, typical elderly Japanese intake more fish than meat, and they tend to prefer chopping and stirfrying meat than grilling [23, 24]. Furthermore, foods that contribute to HAA intake differ by country [25] and, therefore, dietary assessment tools for HAA intake should be tailored specifically for the population being studied. In this study, we used a validated assessment FFQ to assess dietary HAAs in our Japanese cohorts [25, $37,38]$, and we found that high HAA intake was associated with an increased risk of prostate cancer as follows: total HAA intake (OR, 1.90; 95\% CI, 1.40-2.59), Trp-P-1 (OR, 1.92; 95\% CI, 1.42-2.61), MeIQ (OR, 1.87; 95\% CI, 1.38-2.55), MeIQx (OR, 2.25; 95\% CI, 1.65-3.06), and PhIP (OR, 1.84; 95\% CI, 1.35-2.50) (Table 3). In previous studies, which were not Japanese cohort research, no data or significant associations in prostate cancer were observed for dietary Trp-P-1, MeIQ, or MeIQx [3, $4,43,44]$. A statistically significant association between PhIP and prostate cancer risk was observed in one study [44]; however, null or opposed associations were reported in another study [3, 4, 45]. Thus, the present study is the first to report an association between dietary HAA intake and prostate cancer in a Japanese cohort, and it is epidemiologically plausible that high HAA intake is a risk factor of prostate cancer in Japan.

Regarding HAA metabolism, NAT2 is a phase II enzyme that detoxifies HAA carcinogens, is expressed predominantly in the liver, and is highly polymorphic in humans [13]. It was observed that the frequency of NAT2 genotypes varies by population [27]. A previous study showed that the NAT2 slow acetylator phenotype presents decreased enzymatic activity compared with the activity levels of the rapid or intermediate genotypes [46]. As a result, the NAT2 slow acetylator phenotype is considered to reduce hepatic $\mathrm{N}$-acetylation (detoxification) and increase the chance of hepatic N-hydroxylation (activation) [31]. One meta-analysis showed that there was no evidence of an association between NAT2 polymorphisms and prostate cancer in a combined analysis, but there was an association in Asian populations based on racial subgroup analysis [47]. In our study, we found that the NAT2 slow acetylator phenotype was associated with an increased risk of prostate cancer (OR, 1.65; 95\% CI, 1.04-2.61) (Table 4) and that the NAT2 slow acetylator phenotype (OR, 5.29; 95\% CI, 2.37-11.80; $P$ for interaction, 0.004) was higher than rapid or intermediate acetylator phenotypes (OR, 1.85; 95\% CI, 1.34-2.56) among individuals with high HAA intake (Table 5). We posit that this finding indicates that individuals with the NAT2 slow acetylator phenotype have reduced detoxification of HAA carcinogens and increased chance of carcinogen activation, compared with other acetylator phenotypes in individuals with prostate cancer. Although NAT2 is expressed in prostate epithelium and the liver [13], our results suggest that the expression of the NAT2 phenotype in the liver has greater metabolic influence on HAA carcinogens of prostate cancer than its expression in the prostate.

CYP1A1 is a member of the phase I cytochrome $\mathrm{P} 450$ family, which is highly active in the liver, acting on the metabolic activation of HAAs [28]. Similar to NAT2, CYP1A1 mRNA is also expressed in prostate tissue [4850]. CYP1A1 in individuals harboring the mutant $\mathrm{G}$ allele (GA or GG genotype) in exon 7, which substitutes valine for isoleucine, has a higher catalytic activity compared to that found in individuals who are homozygous AA [51]. Findings from a previous study suggested that the CYP1A1 GA + GG genotype confers susceptibility to prostate cancer and that individuals with the CYP1A1 GG genotype have a significantly increased risk [29, 52]. Further, a meta-analysis study showed using subgroup analysis that the CYP1A1 GA + GG genotypes were associated with prostate cancer risk in Asians [53]. Similarly, in our study, we found that the CYP1A1 GA + GG genotypes were associated with prostate cancer risk (OR, 1.27; 95\% CI, 1.02-1.59) (Table 4), and this evidence of an association was observed not only in the high HAA intake group (OR, 2.86; 95\% CI, 1.83-4.47), but also in even the low (OR, 2.05; 95\% CI, 1.19-3.63) and moderate (OR, 1.72; 95\% CI, 1.07-2.76) HAA intake groups (Table 5). These findings provide further support that there is a relationship between $C Y P 1 A 1 \mathrm{GA}+\mathrm{GG}$ genotypes and an enhanced effect on HAA carcinogens in prostate cancer. The second possibility is that this CYP1A1 polymorphism is an independent risk factor for prostate cancer.

Similar to $C Y P 1 A 1, C Y P 1 A 2$ is a phase I metabolizing enzyme that plays a prominent role in the activation of HAA carcinogens [28], and it is also expressed in prostate tissue $[49,50]$. CYP1A2 in individuals with the A allele (CA or AA genotype) has a higher enzymatic activity compared to that found in individuals who are homozygous CC [54]. A previous study showed that the CYP1A2 $\mathrm{CC}$ genotype may be associated with risk of prostate cancer but the finding was not statistically significant [29]. It 
is unclear how reduced CYP1A2 activity contributes to an increased risk of prostate cancer. Nevertheless, in contrast to past findings, we found that the CYP1A2 AA, CA, and $\mathrm{CA}+\mathrm{AA}$ genotypes were associated with an increased risk of prostate cancer (Table 4) and that the CYP1A2 CA + AA genotype (OR, 4.01; 95\% CI, 1.60-10.05; $P$ for interaction, 0.003 ) was higher than the CC genotype (OR, 2.65; 95\% CI, 0.97-7.29) among individuals with high HAA intake, even though the CC genotype OR is not statistically significant, we still can find the trend (Table 5). These findings support that CYP1A2-induced higher activation of HAAs in the liver and/or prostate is important for increased risk of prostate cancer. However, considering its opposition to past findings, future studies testing larger Japanese cohorts are warranted to replicate these findings, and further research is needed to understand how CYP1A2 polymorphisms metabolically influence HAA carcinogens.

There are several limitations of our study. First, an inherent challenge in case control studies is to minimize the influence of selection and information bias (e.g., recall bias), although in our study, the controls were not only population- and age-matched but also were recruited from the same city area (metropolitan Tokyo). Second, although we analyzed each individual polymorphism, we did not investigate the putative effects of different polymorphism combinations because of the modest sample size of our cohorts. Third, because we did not directly determine HAA metabolic reactions in prostate tissue or other organs such as the liver, the effects or contributions of other metabolic pathways cannot be excluded. Nevertheless, to our knowledge, this is the first study to investigate the relationship between HAA intake, functional gene polymorphisms related to the HAA metabolic pathway, and prostate cancer risk in Japanese men.

\section{Conclusions}

In summary, we performed a secondary data analysis of an observational case control study to determine the relationships between HAA intake and specific polymorphisms in three genes to prostate cancer in Japanese men. Based on our analysis, we found that high HAA intake was significantly associated with increased prostate cancer risk. In addition, we found that the NAT2 slow acetylator phenotype, the CYP1A1 GA + GG genotype, and the CYP1A2 CA + AA genotype were associated with increased prostate cancer risk. In particular, the CYP1A1 GA + GG genotype had increased risk even in the low and moderate HAA intake groups. These findings indicate that high HAA intake is a risk factor of prostate cancer in Japanese men, and that the genotypes of NAT2, CYP1A1, and CYP1A2 may affect the degree of cancer risk via changes in HAA-metabolizing enzymes.

\section{Abbreviations}

4,8-DiMelQx: 2-Amino-3, 4, 8-trimethylimidazo[4, 5-f]quinoxaline; 7,8-

DiMelQx: 2-Amino-3, 7, 8-trimethylimidazo[4, 5-f]quinoxaline; 95\% Cl: 95\% Confidence interval; BMI: Body mass index; CYP: Cytochrome P450;

FFQ: Food frequency questionnaire; HAA: Heterocyclic aromatic amine; IQ: 2-Amino-3-methylimidazo[4, 5-f]quinoline; MelQ: 2-Amino-3, 4-

dimethylimidazo[4, 5-f]quinoline; MelQx: 2-Amino-3, 8-dimethylimidazo[4, 5-f]quinoxaline; NaCl: Sodium chloride; NAT1: N-acetyltransferase 1; NAT2: Nacetyltransferase 2; OR: Odds ratio; PhIP: 2-Amino-1-methyl- 6-

phenylimidazo[4,5-b]pyridine; SD: Standard deviation; SNP: Single nucleotide polymorphism; Trp-P-1: 3-Amino-1, 4-dimethyl-5H-pyrido[4, 3-b]indole; UTR: Untranslated region

\section{Acknowledgements}

We thank all the staff of the Mitsui Memorial Hospital and the Jikei University School of Medicine Hospital for their outstanding support. We also thank Dr. Kemmyo Sugiyama MD, Ph.D., of Toshoku University for his critical advice on our statistical analysis and Dr. Nahoko Harada RN, Ph.D., of the University of Miyazaki for her advice on the entire project.

\section{Funding}

This study received no specific grant from any funding agency in the public, commercial, or non-profit sectors.

\section{Availability of data and materials}

The datasets generated and/or analyzed during the current study are not publicly available due to ethical considerations but are available from the corresponding author on reasonable request.

\section{Authors' contributions}

MK designed the study, performed the genotyping and statistical analyses, interpreted the data, and drafted the manuscript. XL assisted with the design of the study and checked the manuscript. MI and TK were involved in data collection, assisted with the design of the study, and checked the manuscript. YY participated in the study concept and checked the manuscript. All authors read and approved the final manuscript.

\section{Ethics approval and consent to participate}

The study protocol received ethics approval from the institutional review board of Faculty of Life Sciences, Kumamoto University (Kumamoto, Japan), on June 10, 2016 (approval number 209). Written informed consent was obtained from all participants by the return of the questionnaires.

Participants had the option not to respond to any part of the questionnaire and could discontinue participation at any point.

Consent for publication

Not applicable.

\section{Competing interests}

The authors declare that no competing interests exist.

\section{Publisher's Note}

Springer Nature remains neutral with regard to jurisdictional claims in published maps and institutional affiliations.

\section{Author details}

'Department of Public Health, Faculty of Life Sciences, Kumamoto University, 1-1-1 Honjou, Chuo-ku, Kumamoto 860-8556, Japan. 'Division of Epidemiology, Center for Public Health Sciences, National Cancer Center, Tokyo, Japan. ${ }^{3}$ Department of Hygiene and Preventive Medicine, Showa University School of Medicine, Tokyo, Japan.

Received: 31 August 2017 Accepted: 17 October 2017

Published online: 24 October 2017

\section{References}

1. Abid Z, Cross AJ, Sinha R. Meat, dairy, and cancer. Am J Clin Nutr. 2014;100: 386S-93S.

2. World Cancer Research Fund/American Institute for Cancer Research. Food, nutrition, physical activity, and the prevention of cancer: a global perspective. Washington DC: AICR; 2007. 
3. Sinha R, Park Y, Graubard BI, Leitzmann MF, Hollenbeck A, Schatzkin A, et al. Meat and meat-related compounds and risk of prostate cancer in a large prospective cohort study in the United States. Am J Epidemiol. 2009:170:1165-77.

4. Koutros S, Cross AJ, Sandler DP, Hoppin JA, Ma X, Zheng T, et al. Meat and meat mutagens and risk of prostate cancer in the agricultural health study. Cancer Epidemiol Biomark Prev. 2008;17:80-7.

5. Alexander DD, Mink PJ, Cushing CA, Sceurman B. A review and meta-analysis of prospective studies of red and processed meat intake and prostate cancer. Nutr J. 2010;9:50.

6. Sugimura T, Wakabayashi K, Nakagama H, Nagao M. Sugimura T, Wakabayashi $\mathrm{K}$, et al. Heterocyclic amines: mutagens/carcinogens produced during cooking of meat and fish. Cancer Sci 2004;95:290-299.

7. Xiao S, Guo J, Yun BH, Villalta PW, Krishna S, Tejpaul R, et al. Biomonitoring DNA adducts of cooked meat carcinogens in human prostate by nano liquid chromatography-high resolution tandem mass spectrometry: identification of 2-amino-1-methyl-6-phenylimidazo[4,5-b]pyridine DNA adduct. Anal Chem. 2016;88:12508-15.

8. Lawson T, Kolar C. Human prostate epithelial cells metabolize chemicals of dietary origin to mutagens. Cancer Lett. 2002;175:141-6.

9. Minchin RF, Reeves PT, Teitel CH, McManus ME, Mojarrabi B, llett KF, et al. Nand O-acetylation of aromatic and heterocyclic amine carcinogens by human monomorphic and polymorphic acetyltransferases expressed in COS-1 cells. Biochem Biophys Res Commun. 1992;185:839-44.

10. Turesky RJ, Lang NP, Butler MA, Teitel CH, Kadlubar FF. Metabolic activation of carcinogenic heterocyclic aromatic amines by human liver and colon. Carcinogenesis. 1991;12:1839-45.

11. Chou HC, Lang NP, Kadlubar FF. Metabolic activation of N-hydroxy arylamines and $\mathrm{N}$-hydroxy heterocyclic amines by human sulfotransferase(s). Cancer Res. 1995;55:525-9.

12. Nagaoka H, Wakabayashi K, Kim SB, Kim IS, Tanaka Y, Ochiai M, et al. Adduct formation at $\mathrm{C}-8$ of guanine on in vitro reaction of the ultimate form of $2-$ amino-1-methyl-6-phenylimidazo[4,5-b]pyridine with 2'-deoxyguanosine and its phosphate esters. Jpn J Cancer Res. 1992:83:1025-9.

13. Wang CY, Debiec-Rychter M, Schut HA, Morse P, Jones RF, Archer C, et al. Nacetyltransferase expression and DNA binding of $N$-hydroxyheterocyclic amines in human prostate epithelium. Carcinogenesis. 1999;20:1591-5.

14. Di Paolo OA, Teitel CH, Nowell S, Coles BF, Kadlubar FF. Expression of cytochromes P450 and glutathione S-transferases in human prostate, and the potential for activation of heterocyclic amine carcinogens via acetylCOA-, PAPS- and ATP-dependent pathways. Int J Cancer 2005;117:8-13.

15. Tang D, Liu JJ, Rundle A, Neslund-Dudas C, Savera AT, Bock CH, et al. Grilled meat consumption and PhIP-DNA adducts in prostate carcinogenesis. Cancer Epidemiol Biomark Prev. 2007;16:803-8.

16. Tang D, Kryvenko ON, Wang Y, Trudeau S, Rundle A, Takahashi S, et al. 2-Amino1-methyl-6-phenylimidazo[4,5-b]pyridine (PhIP)-DNA adducts in benign prostate and subsequent risk for prostate cancer. Int J Cancer. 2013;133:961-71.

17. Rohrmann S, Nimptsch K, Sinha R, Willett WC, Giovannucci EL, Platz EA, et al. Intake of meat mutagens and risk of prostate cancer in a cohort of U.S. health professionals. Cancer Epidemiol Biomark Prev. 2015;24:1557-63.

18. Bylsma LC, Alexander DD. A review and meta-analysis of prospective studies of red and processed meat, meat cooking methods, heme iron, heterocyclic amines and prostate cancer. Nutr J. 2015;14:125.

19. Skog Kl, Johansson MA, Jägerstad MI. Carcinogenic heterocyclic amines in model systems and cooked foods: a review on formation, occurrence and intake. Food Chem Toxicol. 1998;36:879-96.

20. Iwasaki M, Kataoka H, Ishihara J, Takachi R, Hamada GS, Sharma S, et al. Heterocyclic amines content of meat and fish cooked by Brazilian methods. J Food Compost Anal. 2010;23:61-9.

21. Allen NE, Sauvaget C, Roddam AW, Appleby P, Nagano J, Suzuki G, et al. A prospective study of diet and prostate cancer in Japanese men. Cancer Causes Control. 2004;15:911-20

22. Severson RK, Nomura AM, Grove JS, Stemmermann GN. A prospective study of demographics, diet, and prostate cancer among men of Japanese ancestry in Hawaii. Cancer Res. 1989:49:1857-60.

23. Sasaki S, Kobayashi M, Ishihara J, Tsugane S. Self-administered food frequency questionnaire used in the 5-year follow-up survey of the JPHC Study: questionnaire structure, computation algorithms, and area-based mean intake. J Epidemiol. 2003;13(Suppl 1):S13-22.

24. Tsugane S, Sasaki S, Kobayashi M, Tsubono Y, Sobue T. Dietary habits among the JPHC study participants at baseline survey. Japan public health center-based prospective study on cancer and cardiovascular diseases. J Epidemiol. 2001;11(Suppl 6):S30-43.

25. Kobayashi M, Hanaoka T, Nishioka S, Kataoka H, Tsugane S. Estimation of dietary HCA intakes in a large-scale population-based prospective study in Japan. Mutat Res. 2002;506-507:233-41.

26. McManus ME, Burgess WM, Veronese ME, Huggett A, Quattrochi LC, Tukey $\mathrm{RH}$. Metabolism of 2-acetylaminofluorene and benzo(a)pyrene and activation of food-derived heterocyclic amine mutagens by human cytochromes P-450. Cancer Res. 1990;50:3367-76.

27. Costa S, Pinto D, Morais A, Vasconcelos A, Oliveira J, Lopes C, et al. Acetylation genotype and the genetic susceptibility to prostate cancer in a southern European population. Prostate. 2005;64:246-52.

28. Kim D, Guengerich FP. Cytochrome P450 activation of arylamines and heterocyclic amines. Annu Rev Pharmacol Toxicol. 2005;45:27-49.

29. Murata M, Watanabe M, Yamanaka M, Kubota $Y$, Ito H, Nagao M, et al. Genetic polymorphisms in cytochrome P450 (CYP) 1A1, CYP1A2, CYP2E1, glutathione S-transferase (GST) M1 and GSTT1 and susceptibility to prostate cancer in the Japanese population. Cancer Lett. 2001;165:171-7.

30. Smith G, Stanley LA, Sim E, Strange RC, Wolf CR. Metabolic polymorphisms and cancer susceptibility. Cancer Surv. 1995;25:27-65.

31. Hein DW, Doll MA, Fretland AJ, Leff MA, Webb SJ, Xiao GH, et al. Molecular genetics and epidemiology of the NAT1 and NAT2 acetylation polymorphisms. Cancer Epidemiol Biomark Prev. 2000;9:29-42.

32. Yang M, Katoh T, Delongchamp R, Ozawa S, Kohshi K, Kawamoto T. Relationship between NAT1 genotype and phenotype in a Japanese population. Pharmacogenetics. 2000;10:225-32.

33. O'Neil WM, Drobitch RK, MacArthur RD, Farrough MJ, Doll MA, Fretland AJ, et al. Acetylator phenotype and genotype in patients infected with HIV: discordance between methods for phenotype determination and genotype. Pharmacogenetics. 2000;10:171-82.

34. Hein DW, Doll MA, Rustan TD, Ferguson RJ. Metabolic activation of Nhydroxyarylamines and $\mathrm{N}$-hydroxyarylamides by 16 recombinant human NAT2 allozymes: effects of 7 specific NAT2 nucleic acid substitutions. Cancer Res. 1995;55:3531-6.

35. Hein DW, Ferguson RJ, Doll MA, Rustan TD, Gray K. Molecular genetics of human polymorphic N-acetyltransferase: enzymatic analysis of 15 recombinant human wild-type, mutant, and chimeric NAT2 allozymes. Hum Mol Genet. 1994;3:729-34.

36. Hein DW, Leff MA, Ishibe N, Sinha R, Frazier HA, Doll MA, et al. Association of prostate cancer with rapid $\mathrm{N}$-acetyltransferase $1\left(\right.$ NAT $\left.1^{* 1} 10\right)$ in combination with slow $\mathrm{N}$-acetyltransferase 2 acetylator genotypes in a pilot case-control study. Environ Mol Mutagen. 2002;40:161-7.

37. Kobayashi M, Hanaoka T, Tsugane S. Validity of a self-administered food frequency questionnaire in the assessment of heterocyclic amine intake using 2-amino-1-methyl-6-phenylimidazo[4,5-b]pyridine (PhIP) levels in hair. Mutat Res. 2007:630:14-9.

38. Iwasaki M, Mukai T, Takachi R, Ishihara J, Totsuka Y, Tsugane S. Validity of a self-administered food frequency questionnaire in the estimation of heterocyclic aromatic amines. Cancer Causes Control. 2014;25:1015-28.

39. Mucci LA, Signorello LB, Adami H-O. Prostate cancer. In: Adami H-O, Hunter D, Trichopoulos D, editors. Textbook of cancer epidemiology. 2nd ed. New York: Oxford University Press; 2008. p. 517-54.

40. Damber JE, Aus G. Prostate cancer. Lancet. 2008;371:1710-21.

41. Shah S. An update on the risk factors for prostate cancer. WCRJ. 2016;3:e711.

42. Willett W, Stampfer MJ. Total energy intake: implications for epidemiologic analyses. Am J Epidemiol. 1986;124:17-27.

43. Kazerouni N, Sinha R, Hsu CH, Greenberg A, Rothman N. Analysis of 200 food items for benzo[a]pyrene and estimation of its intake in an epidemiologic study. Food Chem Toxicol. 2001;39:423-36.

44. Cross AJ, Peters U, Kirsh VA, Andriole GL, Reding D, Hayes RB, et al. A prospective study of meat and meat mutagens and prostate cancer risk. Cancer Res. 2005;65:11779-84.

45. Major JM, Cross AJ, Watters JL, Hollenbeck AR, Graubard BI, Sinha R. Patterns of meat intake and risk of prostate cancer among African-Americans in a large prospective study. Cancer Causes Control. 2011;22:1691-8.

46. Cascorbi I, Drakoulis N, Brockmöller J, Maurer A, Sperling K, Roots I. Arylamine $\mathrm{N}$-acetyltransferase (NAT2) mutations and their allelic linkage in unrelated Caucasian individuals: correlation with phenotypic activity. Am J Hum Genet. 1995;57:581-92.

47. Gong C, Hu X, Gao Y, Cao Y, Gao F, Mo Z. A meta-analysis of the NAT1 and NAT2 polymorphisms and prostate cancer: a huge review. Med Oncol. 2011;28:365-76 
48. Mitsui Y, Chang I, Kato T, Hashimoto Y, Yamamura S, Fukuhara S, et al. Functional role and tobacco smoking effects on methylation of CYP1A1 gene in prostate cancer. Oncotarget. 2016;7:49107-21.

49. Finnström N, Bjelfman C, Söderström TG, Smith G, Egevad L, Norlén BJ, et al. Detection of cytochrome P450 mRNA transcripts in prostate samples by RTPCR. Eur J Clin Investig 2001;31:880-886.

50. Sterling KM Jr, Cutroneo KR. Constitutive and inducible expression of cytochromes P4501A (CYP1A1 and CYP1A2) in normal prostate and prostate cancer cells. J Cell Biochem. 2004;91:423-9.

51. Crofts F, Taioli E, Trachman J, Cosma GN, Currie D, Toniolo P, et al. Functional significance of different human CYP1A1 genotypes. Carcinogenesis. 1994;15:2961-3

52. Murata M, Shiraishi T, Fukutome K, Watanabe M, Nagao M, Kubota Y, et al. Cytochrome P4501A1 and glutathione S-transferase M1 genotypes as risk factors for prostate cancer in Japan. Jpn J Clin Oncol. 1998;28:657-60.

53. Han G, Ma Y, Liu P, Wei X, Zhang X, Zhu F. Quantitative synthesis of the association between the cytochrome P450 1A1 Ie462Val polymorphism and prostate cancer risk. Tumour Biol. 2013;34:1511-6.

54. Sachse C, Brockmöller J, Bauer S, Roots I. 1999. Functional significance of a $\mathrm{C} \rightarrow \mathrm{A}$ polymorphism in intron 1 of the cytochrome P450 CYP1A2 gene tested with caffeine. Br J Clin Pharmacol 1999;47:445-449.

\section{Submit your next manuscript to BioMed Central} and we will help you at every step:

- We accept pre-submission inquiries

- Our selector tool helps you to find the most relevant journal

- We provide round the clock customer support

- Convenient online submission

- Thorough peer review

- Inclusion in PubMed and all major indexing services

- Maximum visibility for your research

Submit your manuscript at www.biomedcentral.com/submit 